\title{
MANUFACTURING AND EVALUATING OF A LOCAL SHREDDING UNIT ATTACHED WITH A CARRIAGE IRRIGATION MACHINE
}

\author{
Abd Allah W. E. ${ }^{1}$, Awny A. ${ }^{1}$ and Metwally K. A. ${ }^{2}$
}

\section{ABSTRACT}

In Egypt, many farmers have a carriage irrigation machines operated with a single cylinder diesel engine and used only for irrigation purposes at different periods. So, the aim of this paper is using the diesel engine of the irrigation machine to provide power for an attached small shredding unit which can be delivered its movement from the flywheel of the irrigation machine. The experiments were conducted at three shredding drum speeds of 32.2, 41 and $52.8 \mathrm{m.s}$, three maize average moisture content of 67, 74 and $85 \%$ as well as three different number of shredding knives were 3, 4 and 5. Machine productivity, shredding efficiency, power, specific energy requirements, and saving costs were studied. The obtained results revealed that, the productivity increased by increasing the cutting drum speed and number of knives where the highest productivity is $0.608 \mathrm{Mg} \cdot \mathrm{h}^{-1}$ recorded at cutting drum speed of $52.8 \mathrm{~m} . \mathrm{s}^{-1}$, moisture content of $85 \%$ and using 5 knives. While, the highest shredding efficiency is $95.4 \%$ recorded at cutting drum speed of $52.8 \mathrm{~m} . \mathrm{s}^{-1}$, moisture content of $67 \%$ and using 5 knives. The lowest specific energy of $8.37 \mathrm{kWh} . \mathrm{Mg}^{-1}$ and the highest saving costs of $176.4 \mathrm{~L} . \mathrm{E} . \mathrm{Mg}^{-1}$ were recorded at drum speed of $32.2 \mathrm{~m} . \mathrm{s}^{-1}$, moisture content of $85 \%$ and using 3 knives.

Keywords: Irrigation machine, diesel engine, shredding unit, maize, shredding efficiency, cutting drum, saving costs.

\section{INTRODUCTION}

The fragmentation of agricultural land ownerships to small holdings and farms is considered one of the most important challenges of agricultural mechanization spread in Egypt. According to the statistics of Ministry of Agriculture and Land Reclamation, the total area of agricultural land ownerships is about 7.1 million feddans.

\footnotetext{
${ }^{1}$ Lecturer. Agric. Eng. Dept., Fac. of Agric., Zagazig Univ., Egypt.

${ }^{2}$ Lecturer, Soil and Water Sci. Dept., Fac. of Technology and Development, Zagazig Univ., Egypt.
} 
The percentage of these holdings that lower than 5 feddans is about of $53 \%$ from the total area for about 3.5 million of ownership farmers. Supposedly, each one of those farmers needs to own a tractor for each piece of land, whereas the agricultural tractor is the main power source provider in the farm. In fact, the number of agricultural tractors already in Egypt for this category (equal or lower than $60 \mathrm{hp}$ ) is about of 96.5 thousands (CAPMAS, 2014) although this number is mostly found in companies or government sector. Most of Egyptian farmers have not been able to buy tractors, so, they depend on their manual efforts or tractor rental in all agricultural operations.

From another point of view, the simple Egyptian farmer suffers the high cost of the processed livestock feed, so his thinking tends to exploit these small holdings for planting green fodder (mainly sorghum and maize). But he finds a problem in providing such feed when presented as it is to animals in his farm because the animals eat only green leaves and leave stems, whereas it is difficult to eat and digest the complete stalks of maize in particular. Accumulation of these stems and plant residues or using it in direct burning shall cause environmental and health problems. Therefore, it is necessary to provide the simple farmer with a low cost local manufactured shredding unit, but the problem of providing the power source is still remains, whereas either renting a tractor to operate this unit or using an electrical motor.

Basiouny et. al. (2013) modified a local thresher (El-shams thresher model) for chopping crop residues of rice straw and cotton stalks and evaluated the performance of the machine. They were studied the effect of four cutting rotor speeds and three stalk moisture contents on cutting length, cutting efficiency, productivity, total machine losses, estimation of power, energy requirements, operating cost and criterion function cost. Results revealed that, cutting length less than $3 \mathrm{~cm}$ increased by increasing cutting rotor speed and decreasing stalks moisture content. The lowest values of energy requirement were 24.63 and $16.26 \mathrm{kWh} \cdot \mathrm{Mg}^{-1}$ for rice straw and cotton stalks, respectively. The minimum values of criterion cost were 74.68 and 61.67 L.E. $\mathrm{Mg}^{-1}$ for cutting rice straw and cotton stalks, respectively. 
EL-Attar et al. (2013) studied the effect of four cutter head speeds, three numbers of knives, three levels of corn stalks moisture on corn stalks chopper quality. The performance of chopper as chopping length, degree of destruction, machine productivity and energy were measured and the results revealed that, increasing of cutter head speed from 22.1 to 35.3 $\mathrm{m} . \mathrm{s}^{-1}$ tend to increase percentage of chopping length $(0.5$ to $2 \mathrm{~cm})$ from 50 to $60 \%$; degree of destruction from 28.7 to $38.2 \%$; machine productivity from 1.32 to $2.81 \mathrm{Mg} \cdot \mathrm{h}^{-1}$; useful power from 2.19 to 3.86 $\mathrm{kW}$, meanwhile decreasing the required unit energy from 1.87 to 1.37 $\mathrm{kWh} . \mathrm{Mg}^{-1}$ and chopping machine cost from 16.33 to $7.22 \mathrm{~L}$.E. $\mathrm{Mg}^{-1}$ at knives number of two and corn stalk moisture content of $65.0 \%$.

Elfatih et al. (2010) evaluated a rice straw chopper for composting and studied the effect of cutting drum speed and concave holes diameter on cutting efficiency, chopper productivity, power requirement, energy consumption and composting period. They found that, increasing of cutting drum linear speed from 56.6 to $70.7 \mathrm{~m} . \mathrm{s}^{-1}$ tends to increase cutting efficiency, chopper productivity, and power requirement by percentages of $(3.7,2.8$ and $0.9 \%),(57.5,55.9$ and $41.7 \%)$, (36.8, 28.6 and 35.9\%), respectively, meanwhile, decrease energy consumption by percentages of (32.7, 38.4 and $9 \%$ ) for 35,25 and $9 \mathrm{~mm}$ of concave hole diameter, respectively. The highest cost was 240.7 L.E. $\mathrm{Mg}^{-1}$ while the lowest cost was 129.2 L.E. $\mathrm{Mg}^{-1}$.

Zhang et al. (2003) designed and evaluated a corn silage harvester using shredding and flail cutting for improving the feed value of corn silage. They showed that, the average required specific energy to shred wholeplant corn ranged from 2.5 to $5.9 \mathrm{kWh} . \mathrm{Mg}^{-1}$. Also the average specific energy for an added flail cutter/blower ranged from 2.0 to $4.7 \mathrm{kWh} . \mathrm{Mg}^{-1}$ for a total harvester specific energy requirement of 4.5 to $10.6 \mathrm{kWh} \cdot \mathrm{Mg}^{-1}$. Omran (2008) studied the performance of the most widely used shredders in Egypt such as local shredder manufactured in Kader-Militry factory, local shredder manufactured in Mabrouk-International company and Vermeer made in USA to shred the most important crops residues such as (rice straw, cotton stalks and maize stalks) for feeding livestock, composting or briquetting production. The three studied machines were operated by Massy Ferguson tractor $(60 \mathrm{hp})$. under cutting rotor speeds 
ranging from 1000 to $2000 \mathrm{rpm}$. The comparison was based on productivity, consumed energy, cutting lengths and total costs the recommendation of this study was the local shredder (Mabrok) was the most appropriate shredder to work with rice, cotton and maize residues.

Arfa (2007) modified and evaluated a stationary thresher machine for chopping and cutting farm crop residues using three different feeding rates $0.5,1$ and $1.5 \mathrm{Mg} \cdot \mathrm{h}^{-1}$, three different threshing drum speeds 13.1, 15.71 and $18.33 \mathrm{~m} . \mathrm{s}^{-1}$, three different oval slots area were used 4, 6 and 8 $\mathrm{cm}^{2}$, three different moisture content of rice straw, corn stalks and cotton stalks were used 6.5, 10.2 and $14.3 \%$, three different concave clearance were used 3,4 and $5 \mathrm{~cm}$. The study revealed that the thresher was operated successfully under conditions of oval slots area of $4 \mathrm{~cm}^{2}$, drum speeds of $18.33 \mathrm{~m} . \mathrm{s}^{-1}$, feeding rates of $1.5 \mathrm{Mg} \cdot \mathrm{h}^{-1}$, moisture content of $14.3 \%$ and concave clearance of $3 \mathrm{~cm}$ resulting in cutting length percentage of $82.1,85.6$ and $80.1 \%$ less than $3.5 \mathrm{~cm}$ for rice straw, corn stalks and cotton stalks, respectively. Power consumption and energy requirement were found to be $(43.4,40.3$ and $38.7 \mathrm{~kW})$ and $(28.9,27.3$ and $25.8 \mathrm{kWh} . \mathrm{Mg}^{-1}$ ) for rice straw, corn stalks and cotton stalks, respectively.

This paper proposed to manufacture and operate a local low-cost shredding unit provided with available power source to simple farmers. In this context, it had been noticed that, most of Egyptian farmers have a carriage irrigation machines operated with a single cylinder four-stroke diesel engine, whereas the statistics indicate that, the number of carriage irrigation machines ( 5 to $12 \mathrm{hp}$ ) in Egypt is about 715 thousands (CAPMAS, 2014). From this point, the idea of this paper is emerged whereas, it became easier to optimize using and exploit the diesel engine of the irrigation machine to provide power for an attached small chopping unit which can derive its movement from the flywheel of the irrigation machine. Thus, the farmer can use the irrigation machine engine for two purposes: the first is lifting water from canals for irrigation purposes; the second is cutting and shredding of plant residues and green fodder as an easy and acceptable food for animals feeding in the farm. Therefore, the main objective of this paper is to develop a carriage irrigation machine as a multi-purposes agricultural machine suited with its engine power for 
pumping irrigation water and farm chopping purposes through adding, operating and evaluating an attached simple local manufactured shredding unit to chop maize plants, which can directly presented as a green fodder to the animals or used in silage production.

\section{MATERIALS AND METHODS}

All experiments were carried out at a private workshop in Zagazig, AlSharkia Governorate, Egypt during season of 2017 to maximize the utilization of diesel centrifugal irrigation machine (DCIM) throughout stoppage periods of the lifting the water. Where, the DCIM was provided with a shredder unit to cut and shred maize plants for feeding animals and making silage.

\subsection{Materials:}

\section{Utilized crop:}

Maize variety of Pioneer 30M84 was taken under all treatments

\section{Diesel centrifugal irrigation machine (DCIM):}

A centrifugal irrigation machine (Kirloskar) attached by $10 \mathrm{hp}$ air cooled diesel engine with vertical single cylinder four stroke was developed by attaching a local manufactured shredding unit.

\section{Shredding unit:}

DCIM after developing consisted of a horizontally shaft with length of $370 \mathrm{~mm}$ and $450 \mathrm{~mm}$ of diameter which was fixed by two axial bearing in a parallel direction with the main shaft of DCIM. A flywheel drum was set at the middle of the mentioned shaft. This drum involved a vertical disk with thickness of $15 \mathrm{~mm}$ and $280 \mathrm{~mm}$ of diameter. Different cutting knives with length of $160 \mathrm{~mm}$, width of $70 \mathrm{~mm}$, thickness of $4 \mathrm{~mm}$ and rake angel of $30^{\circ}$ were fixed with equally spaced radially around on the drum. Surrounding case was with two openings of inlet and outlet encircling the drum. At the inlet opening a counter knife was set. At the outlet opening the minced material was throwing away by the centrifugal force of shredding drum. All components of shredder unit were set and fixed by bolts on the main frame of DCIM and the motion was transmitted from DCIM flywheel to the drum of shredder unit by assembly belt pulley with a proper reduction ratio. Figs. 1,2 and 3 show drawing and photos of DCIM before and after developing and their details. 

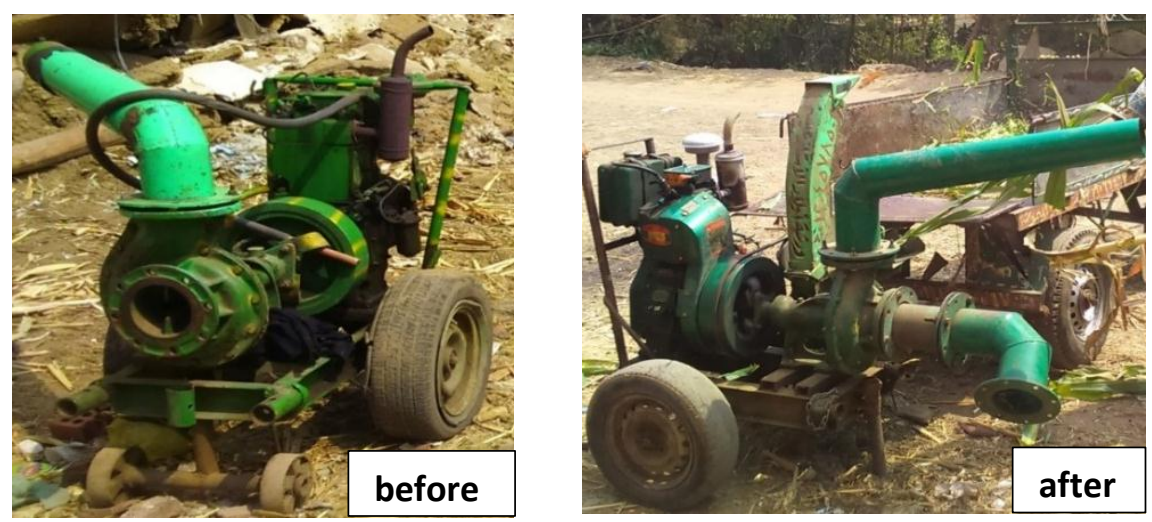

Fig. 1: The DCIM before and after developing.

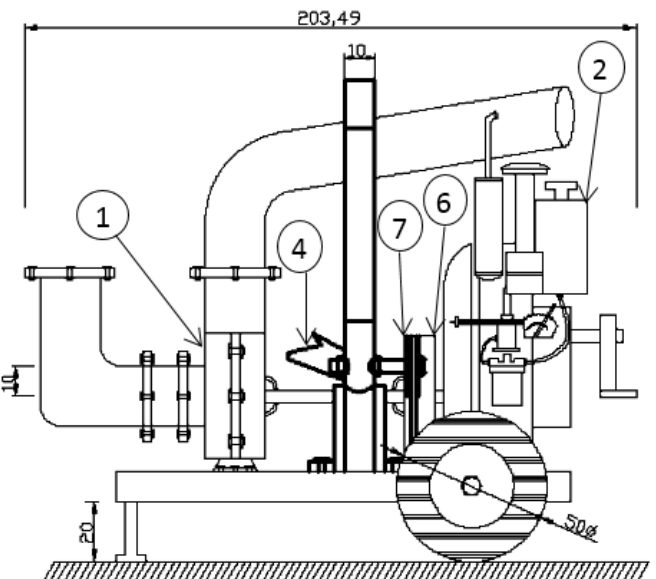

Elev.

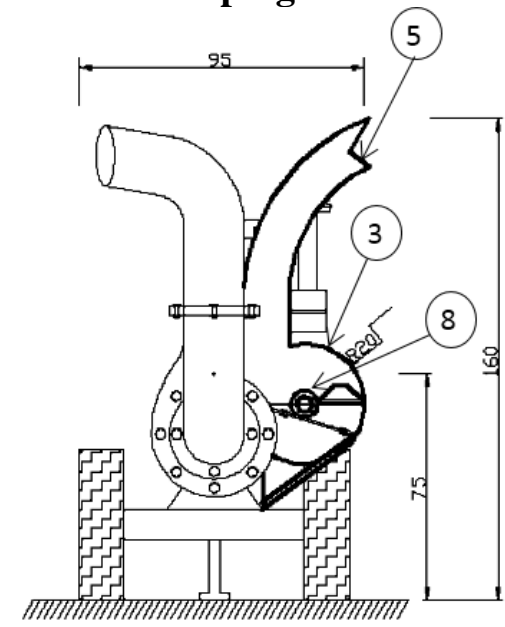

S.V.

Dimentions in, $\mathrm{cm}$

\begin{tabular}{|c|l|c|l|}
\hline NO & \multicolumn{1}{|c|}{ Part name } & NO & \multicolumn{1}{|c|}{ Part name } \\
\hline 1 & Water pump & 5 & Forage outlet \\
\hline 2 & Diesel engine & 6 & Engine flywheel (Drive) \\
\hline 3 & Shredding unite & 7 & Shredding unite flywheel (Driven) \\
\hline 4 & Forage inlet & 8 & Shredding drum shaft \\
\hline
\end{tabular}

Fig. 2: Drawing of the developed DCIM.

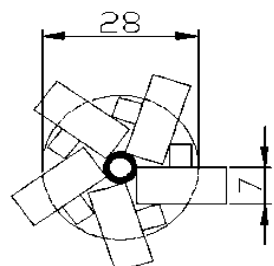

Five knives

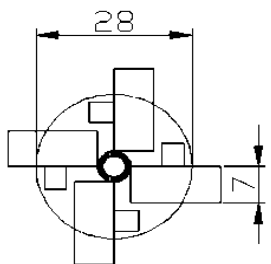

Four knives

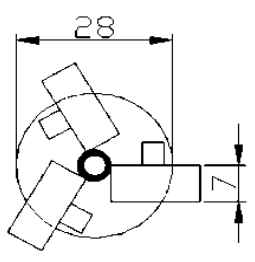

Three knives

Fig. 3: Cutting drum knives. 


\section{Instruments:}

Tachometer, digital vernier, balance, stop watch, electric oven and an assembly electrical measuring fuel consumption were used under all treatments.

\subsection{Methods:}

\subsubsection{Experimental variables:}

- Three shredding drum peripheral speeds were 2200, 2800 and $3600 \mathrm{rpm}\left(32.2,41\right.$ and $52.8 \mathrm{~m} \cdot \mathrm{s}^{-1}$, respectively).

- Three average plants moisture contents were 67, 74 and $85 \%$

- Three numbers of shredding knives were 3, 4 and 5.

\subsubsection{Measurements and determinations:}

\section{Moisture content:}

The moisture content of maize stem and shredding products were measured according to ASAE Standard S.352 (ASAE Year Book, 2002) where the sample kept in the electric oven for 24 hours at $105^{\circ} \mathrm{C}$.

\section{Fuel consumption:}

Fuel consumption was determined by a fabricated and calibrated assembly of fuel consumption which was located between injector and the fuel filter, and experimental data were shown on the analogue monitor of controlled fuel gauge.

The fuel consumption system (Fig. 4) consisted of a float connected with a thin metal leg. The end of the metal leg is mounted to a variable electrical resistor. The electrical resistor connected on one side to the ground (the negative side of battery of 12 VDC). A wiper (sliding contact) connected to the microprocessor that conducts the signal of current to the controlled fuel gauge. If the wiper is closest to the ground side of the electrical circuit; the resistance shall be as low as possible. Thus, the fuel tank is full and the gauge is at its maximum raised position. Vice versa when the wiper is at the other end, the resistance shall be large and the gauge is at its minimum position. The electrical current is sent to the microprocessor that reads the amount of current and translates it into a number indicating the amount of residual fuel. The controlled fuel gauge was accurate calibrated using graduated cylinder to estimate the amount of fuel in the tank (Fig. 5). Then the consumed fuel was estimated as the following equation: 


$$
\mathrm{FC}=\frac{\left(V_{t}-V_{g}\right)}{t}
$$

FC: the consumed fuel $\left(1 . h^{-1}\right)$

$\mathrm{V}_{\mathrm{t}}$ : the full tank volume (1)

$\mathrm{V}_{\mathrm{g}}$ : reading of the electrical gauge of the amount of residual fuel in tank (l)

$\mathrm{t}$ : time of treatment $(\mathrm{h})$

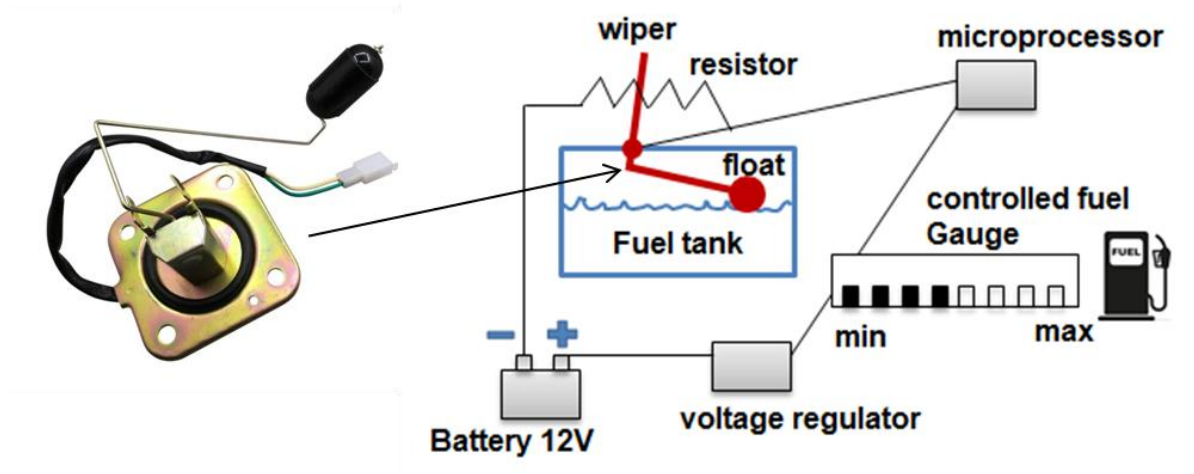

Fig. 4: Fuel consumption assembly.

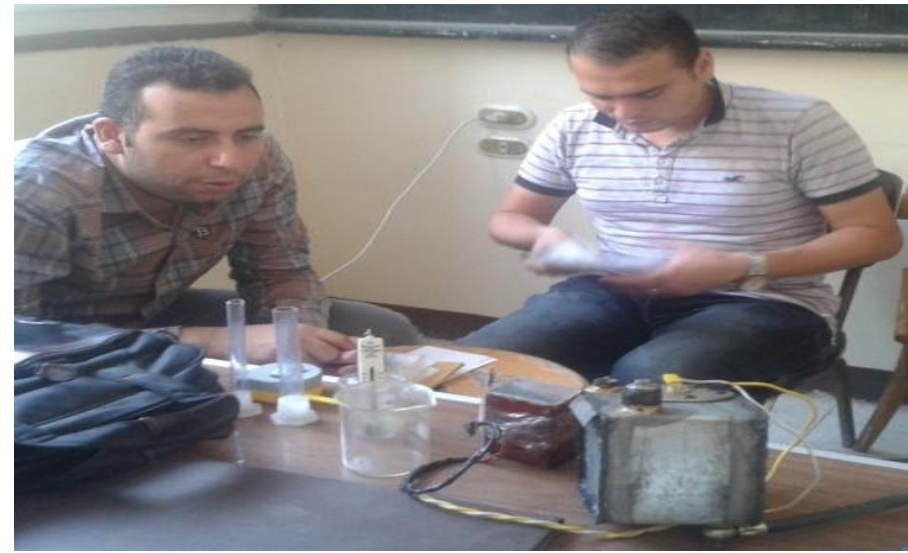

Fig. 5: Photo of calibration of fuel consumption assembly.

Machine productivity:

Machine productivity was calculated by the following equation:

$$
P=\frac{m}{t}, M g h^{-1}
$$

Where,
$\mathrm{P}$ : machine productivity, $\mathrm{Mg} \mathrm{h}^{-1}$
m: mass of crop, $\mathrm{Mg}$
t: operating time, $h$ 


\section{Shredding efficiency:}

After shredding process the efficiency was calculated for all treatments by measuring length of cuts equal to or less than $5 \mathrm{~mm}$ and weighting it $\left(S_{\mathrm{a}}\right)$ divided on total weight of the sample $\left(\mathrm{S}_{\mathrm{b}}\right)$ using the following equation:

$$
\eta_{\mathrm{shr}}=\frac{\mathrm{s}_{\mathrm{a}}}{\mathrm{s}_{\mathrm{b}}} \times 100
$$

Where:

$\eta_{s h r}$ : Shredding efficiency, $\%$

$\mathrm{S}_{\mathrm{a}}$ : weight of the shredding cuts equal to or less than $5 \mathrm{~mm}, \mathrm{~g}$

$\mathrm{S}_{\mathrm{b}}$ : total weight of the shredding treatment sample, $\mathrm{g}$

\section{Required power (Engine power)}

The following formula was used to estimate the engine power:

Engine power $(\mathrm{EP})=3.16 \mathrm{FC}, \mathrm{kW}$.

Where

FC: fuel consumption of treatment, $1 . \mathrm{h}^{-1}$

\section{Specific energy requirements}

The energy requirements can be calculated by the following equation:

Specific energy

$$
=\frac{\text { Required power, } \mathrm{kW}}{\text { Machine productivity, } \mathrm{Mg} \mathrm{h}^{-1}}, \mathrm{~kW} \cdot \mathrm{h} \cdot \mathrm{Mg}^{-1}
$$

\section{Cost analysis:}

The machine cost was determined by using the following equation

(Awady et al., 2003) and prices of 2017 year:

$$
C=\frac{P}{h}\left(\frac{1}{e}+\frac{i}{2}+t+r\right)+(1.2 W . S . F)+\frac{m}{144} .
$$

Where:

C: Machine hourly cost, L.E. $h^{-1}$

P: Price of machine, 15000 L.E. and 20000 L.E. before and after developing, respectively)

h: Yearly working hours, 600 h.year ${ }^{-1}$

e: Life expectancy of the machine, 10 year

i: Annual interest rate, $10 \%$

t: Annual taxes, over heads rate, $2.5 \%$

r: Annual repairs and maintenance rate, $10 \%$

1.2: Factor accounting for ratio of rated power and lubrications. 
$\mathrm{W}$ : Power, kW

S: Specific fuel consumption, $1 . \mathrm{kW}^{-1} \cdot \mathrm{h}^{-1}$

F: Fuel price, 3.65 L.E. $1^{-1}$

m: Operator monthly salary, L.E.

144: The monthly average working hours.

Saving costs of the developed shredder were calculated from following formula:

\section{Hourly saving costs $($ L.E./h $)=[(A+B)-(C+D)]$}

\section{Where:}

A: Hourly cost of shredding by mounted tractor shredder

B: Hourly cost of irrigation by DCIP

C: Hourly cost of shredding by developed DCIP

D: Hourly cost of irrigation by developed DCIP

The hourly cost of mounted tractor shredder was estimated by 70 L.E.h ${ }^{-1}$ according to agricultural mechanization station. While the hourly cost of irrigation by DCIP before and after developing were calculated by Equation (5) and estimated as a constant values by 16.26 and 18.76 L.E. $\mathrm{h}^{-1}$, respectively. But hourly cost of shredding by developed DCIP was calculated by the same equation without labor cost for all treatments. Then the saving criterion costs per one Megagram was calculated by the following formula:

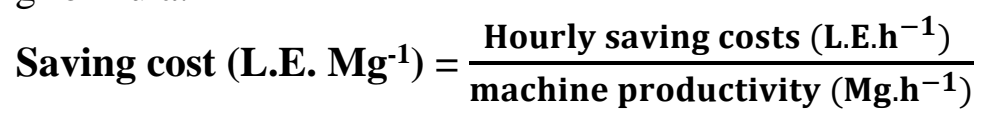

\section{RESULTS AND DISCUSSION}

The obtained results will be discussed as follow:

\subsection{Machine Productivity:}

Fig. 6 shows the effect of cutting drum speed on machine productivity using three different numbers of knives under three moisture contents of maize stalks. The obtained results indicated that, by increasing the cutting drum speed from 32.2 to $52.8 \mathrm{~m} . \mathrm{s}^{-1}$ and increasing number of knives from 3 to 5 , the productivity increased by $38.2 \%$ (from 0.351 to $0.485 \mathrm{Mg}^{-1}$ ),

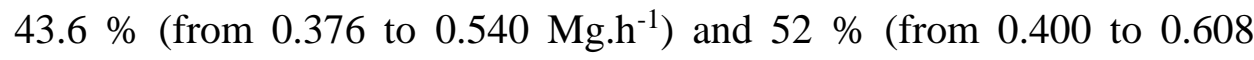

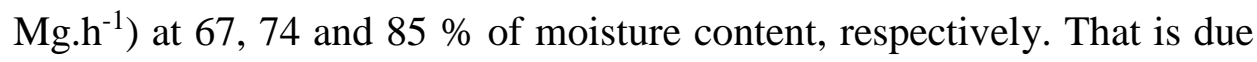
to cutting acceleration of materials by increasing the cutting drum speed, also by increasing the number of cutting knives the machine cut materials 
easy and tend to increase of productivity, this is in agree with the results obtained by EL-Attar et al. (2013). Moreover, increasing moisture content led to increase of productivity due to increasing feeding weight with constant feeding time; as a result of increasing moisture content. So, results revealed that, the highest productivity of $0.608 \mathrm{Mg} \cdot \mathrm{h}^{-1}$ was

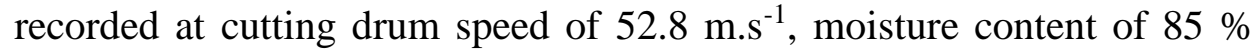
and using 5 knives. while, the lowest productivity is $0.351 \mathrm{Mg} \cdot \mathrm{h}^{-1}$ was

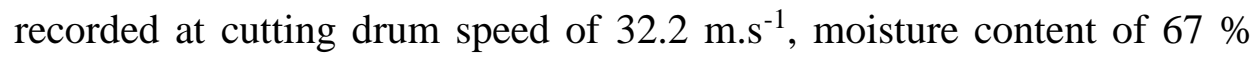
and using 3 knives.

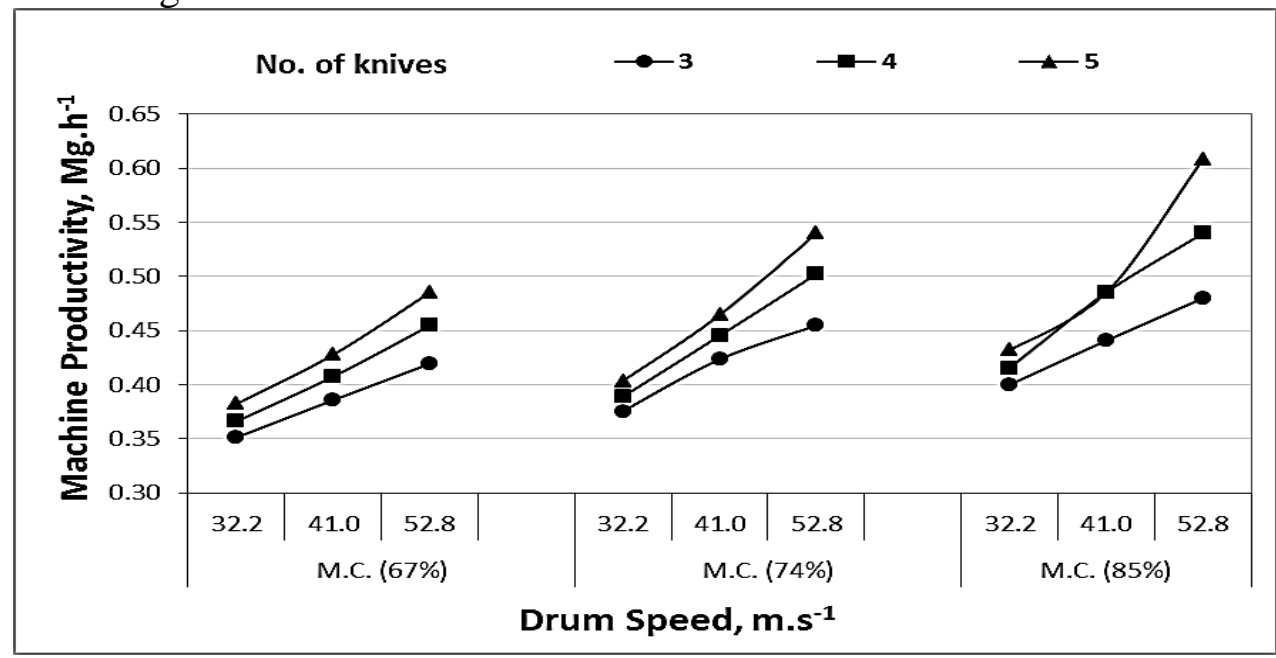

Fig. (6): Effect of cutting drum speed and number of knives on machine productivity at different moisture content of maize.

\subsection{Shredding Efficiency:}

Fig. 7 shows that, the shredding efficiency increased by increasing cutting drum speed and number of knives, meanwhile decreased by increasing the moisture content. The obtained results indicated that, the increase of cutting drum speed from 32.2 to $52.8 \mathrm{~m} . \mathrm{s}^{-1}$ and number of knives from 3 to 5, was followed with an increase in the shredding efficiency from 74.5 to $95.4 \%, 69.3$ to $87.3 \%$ and 66.2 to $84.4 \%$ at 67,74 and $85 \%$ of moisture content, respectively. Whereas the increase of shredding efficiency by increasing cutting drum speed and number of knives this can be attributed to the increase in the number of cuts per unit time and this increases the weight of the suitable cutting length. Additionally, the decrease of shredding efficiency by increasing moisture content as a result of the behavior of visco-elastic material of plant stalk possesses and 
therefore, the stem wall subjected to the maximum shear strength because of the gradual accumulation of lignin inside the stem wall. While the increase of shredding efficiency by decreasing moisture content due to enhancing the stiffness of the stem wall that is as a result of the reduction in moisture content, this is in agree with the results obtained by Srivastava et al. (1995). Therefore, the highest shredding efficiency of $95.4 \%$ was recorded under cutting drum speed of $52.8 \mathrm{~m} . \mathrm{s}^{-1}$, moisture content of $67 \%$ and using 5 knives. While, the lowest efficiency of 66.2 $\%$ was recorded at cutting drum speed of $32.2 \mathrm{~m} . \mathrm{s}^{-1}$, moisture content of $85 \%$ and using 3 knives.

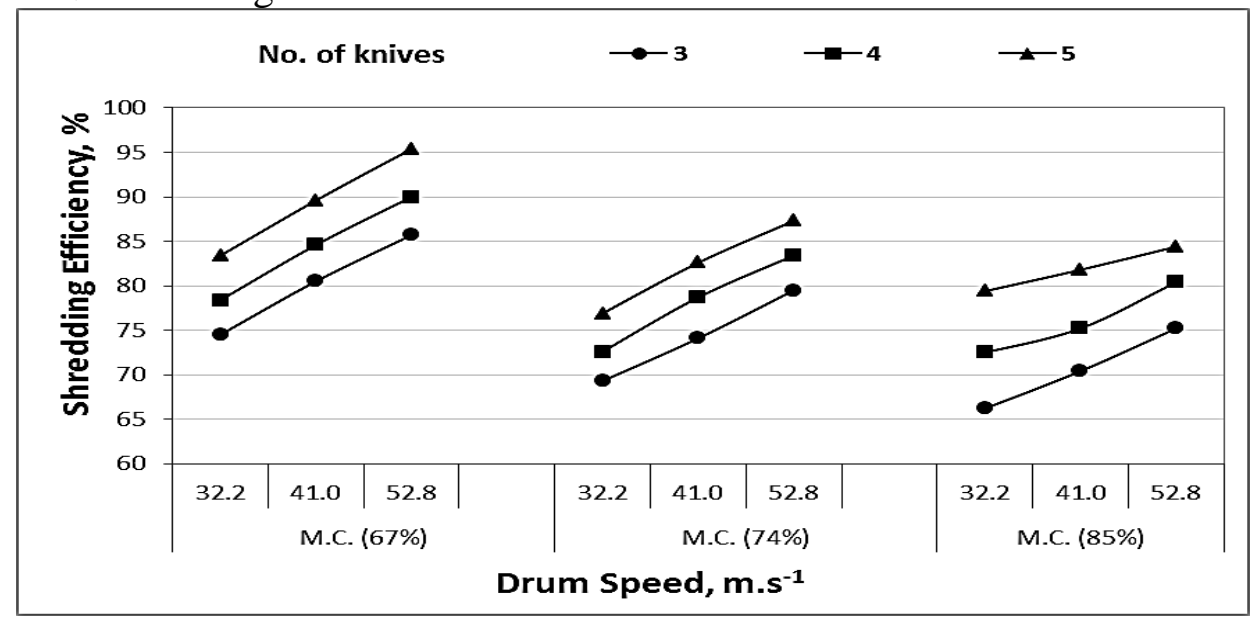

Fig. (7): Effect of cutting drum speed and number of knives on shredding efficiency at different moisture content of maize.

\subsection{Power and Energy Requirements:}

Results of required power and specific energy for shredding maize stalks as affected by different values of cutting drum speed and different numbers of knives at three moisture contents are shown in Fig. 8. From the obtained results, it was noticed that, by increasing the cutting drum speed from 32.2 to $52.8 \mathrm{~m} . \mathrm{s}^{-1}$ and increasing number of knives from 3 to 5 , the required power for shredding maize stalks increased from 3.64 to $5.90 \mathrm{~kW}, 3.28$ to $4.96 \mathrm{~kW}$ and 2.94 to $4.28 \mathrm{~kW}$ at 67,74 and $85 \%$ of moisture content, respectively. Generally, it could be concluded that, the required shredding power decreased as a result of the decrease of fuel consumption when the moisture content increased. Also, when the number of knives increased the required power increased as fuel 
consumption increased. Additionally, when cutting drum speed increased the required power increased, due to increase of fuel consumption. These results agreed with that obtained by Mohamed et al. (1999). Therefore, the higher required power is $5.90 \mathrm{~kW}$ recorded at cutting drum speed of $52.8 \mathrm{~m} . \mathrm{s}^{-1}$, moisture content of $67 \%$ and using 5 knives. Whereas, the lower required power is $2.94 \mathrm{~kW}$ recorded at cutting drum speed of 32.2 $\mathrm{m} . \mathrm{s}^{-1}$, moisture content of $85 \%$ and using 3 knives.

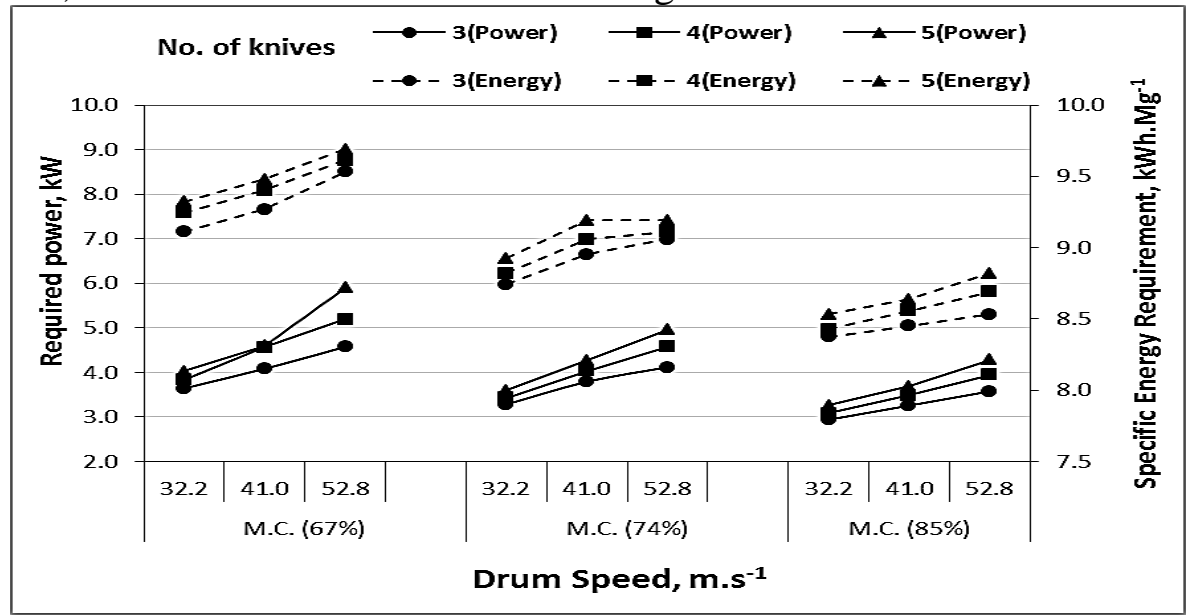

Fig. 8: Effect of cutting drum speed and number of knives on power and required specific energy at different moisture content of maize.

The specific energy $\left(\mathrm{kWh} \cdot \mathrm{Mg}^{-1}\right)$ is the best indicator to show the effect of studied parameters. So, results presented in Fig. 8 indicates the same behavior of required power affected by cutting drum speed, number of knives and moisture content. The specific energy increased by increasing number of knives at constant cutting drum speed and maize stalks moisture content. By increasing the cutting drum speed from 32.2 to 52.8 $\mathrm{m} . \mathrm{s}^{-1}$ and increasing number of knives from 3 to 5 , the specific energy increased from 9.11 to $9.69 \mathrm{kWh} . \mathrm{Mg}^{-1}, 8.74$ to $9.19 \mathrm{kWh}^{-\mathrm{Mg}^{-1}}$ and 8.37 to $8.82 \mathrm{kWh} . \mathrm{Mg}^{-1}$ at 67,74 and $85 \%$ of moisture content of maize, respectively. It was noticed also that, the highest specific energy of 9.69 $\mathrm{kWh} . \mathrm{Mg}^{-1}$ was recorded at cutting drum speed of $52.8 \mathrm{~m} . \mathrm{s}^{-1}$, moisture content of $67 \%$ and using 5 knives. While, the specific energy of 8.82 $\mathrm{kWh} . \mathrm{Mg}^{-1}$ was recorded at cutting drum speed of $32.2 \mathrm{~m} . \mathrm{s}^{-1}$, moisture content of $85 \%$ and using 3 knives. These results agreed with that obtained by Mohamed et al. (1999). 


\subsection{Saving costs:}

Results of the saving cost in the case of using the developed shredding unit for shredding maize stalks as affected by different values of cutting drum speed and different numbers of knives at three moisture contents are shown in Fig. 9. From the obtained results, it was noticed that, the saving costs increased by decrease of cutting drum speed and number of knives, meanwhile increase of moisture content. The obtained results indicated that, by decreasing the cutting drum speed from 52.8 to $32.2 \mathrm{~m} . \mathrm{s}^{-1}$ and number of knives from 5 to 3, the saving costs increased from 92 to 151.6 L.E., 107.7 to 163.2 L.E. and 122.5 to 176.4 L.E. at 67,74 and $85 \%$ of moisture content, respectively.

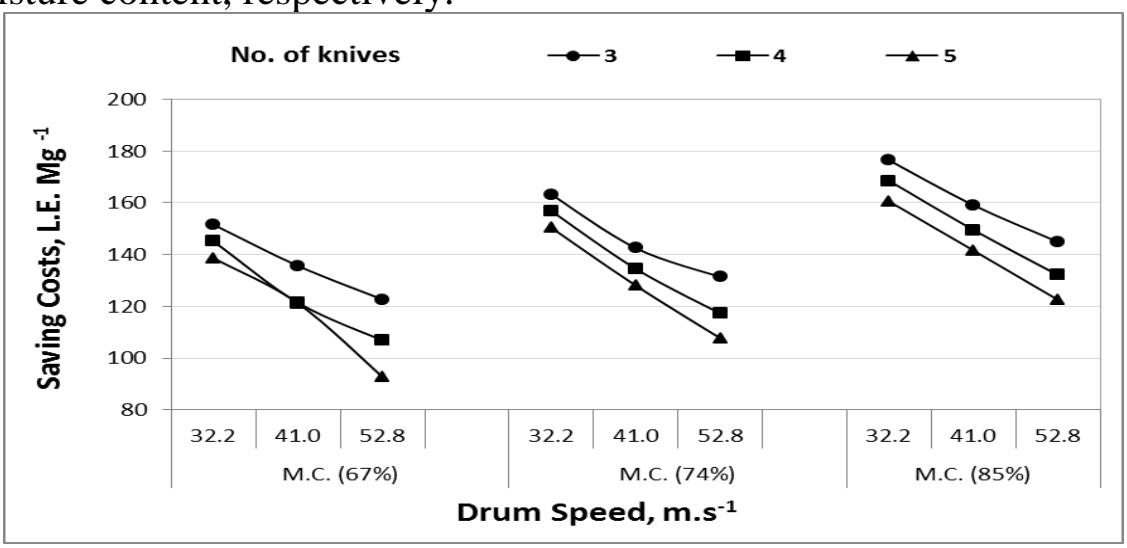

Fig. 9: Effect of cutting drum speed and number of knives on saving costs at different moisture content of maize.

Therefore, the highest saving costs were 176.4 L.E. recorded at cutting drum speed of $32.2 \mathrm{~m} . \mathrm{s}^{-1}$, moisture content of $85 \%$ and using 3 knives. This is due to the lowest specific energy recorded at these conditions. While, the lowest value was 92 L.E. recorded at higher specific energy conditions' at cutting drum speed of $52.8 \mathrm{~m} . \mathrm{s}^{-1}$, moisture content of $67 \%$ and using 5 knives.

\section{CONCLUSION}

The following conclusions can be drawn:

- Attaching the shredding unit to the carriage irrigation machine enhances the utilization efficiency of machine engine's to achieve more one of agricultural operation

- Highest shredding productivity of $0.608 \mathrm{Mg} \cdot \mathrm{h}^{-1}$ obtained at cutting drum speed of $52.8 \mathrm{~m} . \mathrm{s}^{-1}$, moisture content of $85 \%$ and using 5 knives. While the highest shredding efficiency was $95.4 \%$ recorded 
at cutting drum speed of $52.8 \mathrm{~m} . \mathrm{s}^{-1}$, moisture content of $67 \%$ and using 5 knives. Meanwhile the lowest specific energy of 8.82 kWh. $\mathrm{Mg}^{-1}$ as well as highest saving costs of 176.4 L.E. $\mathrm{Mg}^{-1}$ were recorded at cutting drum speed of $32.2 \mathrm{~m} . \mathrm{s}^{-1}$, moisture content of 85 $\%$ and using 3 knives.

- Consequently, it can be recommended to use the manufactured attached shredding unit to irrigation machine instead of the traditional method (rental shredding machines).

\section{REFERENCES}

Arfa. G. K. (2007). Subdual of stationary thresher machine for chopping residues. Misr J. Ag. Eng., 24(3): 504-521.

ASAE (2002). ASAE Standards, 2002a. S358.2: Moisture measurement forages. St. Joseph, Mich.: ASAE.

Awady, M. N; I. Yehia, M. T. Ebaid and E. M. Arif (2003). Development and theory of rice cleaner for reduced impurities and losses. Misr J. Ag. Eng., 20(4): 53-68.

Basiouny, M. A; A. E. El-Yamani and A.E. El- Shazely (2013). Modifying of a local thresher for chopping crop residues. Misr J. Ag. Eng. 3(2): 3-17.

Capmas (2014). Bulletin of agricultural machines 2013. CAPMAS, Cairo, Egypt 29. Capmas (2014), Biannual bulletin on population research and studies, Egypt.

EL-Attar, M. A; S. K. Abd El-Aty and A. A. Soliman (2013). Effect of some operating factors of residues chopper on corn stalks chopper quality. J. Soil Sci. and Agric. Eng., Mansoura Univ., 4 (6): 537 551.

Elfatih A; E. M. Arif, and Atef, A. E. (2010). Evaluate the modified chopper for rice straw composting. Journal of Applied Sciences Research, 6(8): 1125-1131.

Mohamed, M.A; G. H. El-Sayed and K. Hegazy (1999). Some factors affecting power and energy requirements for forage harvesting. Misr J. Agr. Eng., 16 (4): 757-769. 
Omran M. S. (2008). Study of the performance of the most widely used shredders for crops residues in Egypt. The $15^{\text {th }}$ Annual Conference of the Misr Society of Ag. Eng.

Srivastava, A. K; C. E. Goering and R. P. Rohrbach (1995). Engineering principles of agricultural machaines hay and forage harvesting. ASAE Text book number Puplished by the American Society of Agricultural Engineering. Pamela Dover-Honsen. Editor.

Zhang, M; M. L. Sword; D. R. Buckmaster and G. R. Cauffman (2003). Design and evaluation of a corn silage harvester using shredding and flail cutting. Transactions of the ASAE, 46(6): 15031511.

\section{الملخص العربي}

تصنيع وتقييم وحدة فرم محلية الصنع 'ملحقة بماكينة الري النقالي

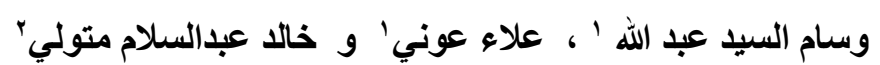

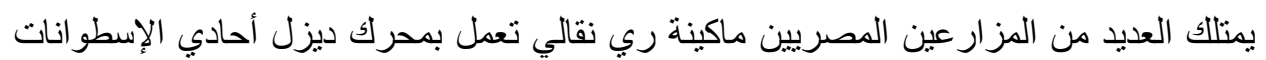

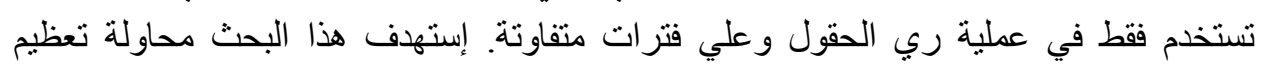

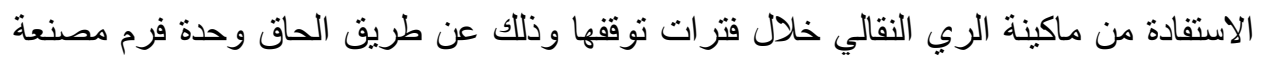

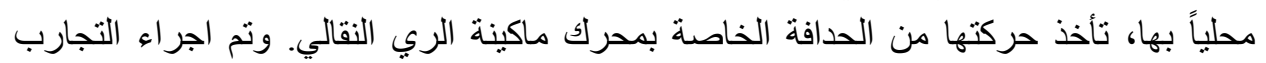

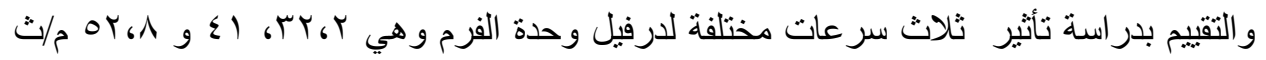

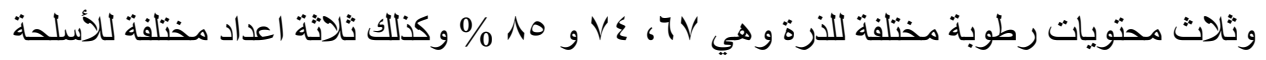

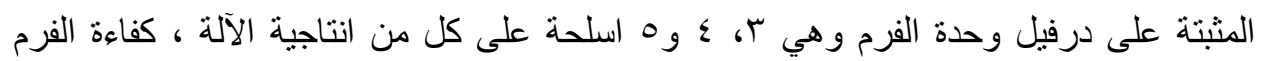

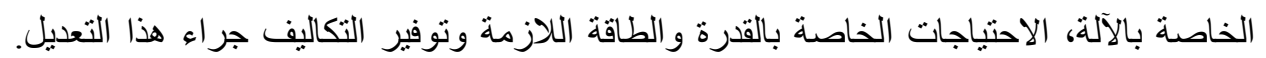

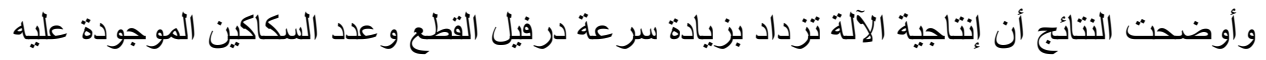

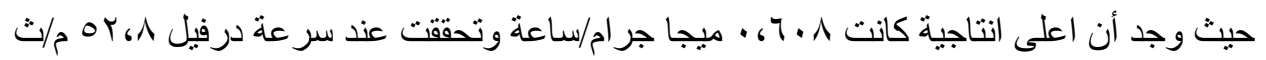

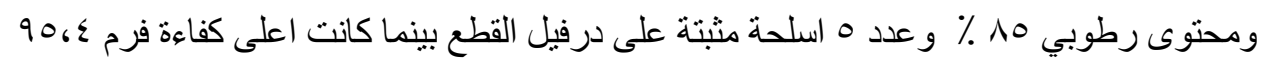

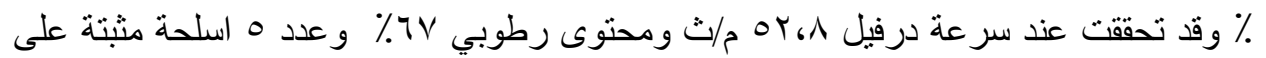

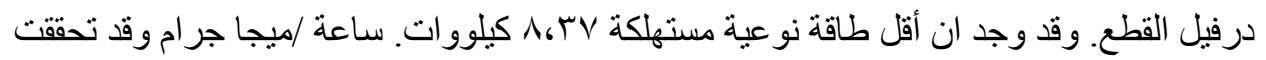

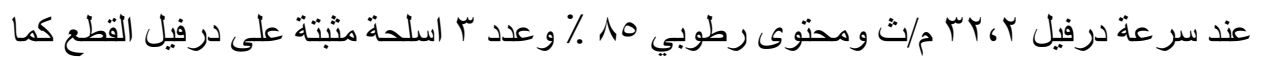

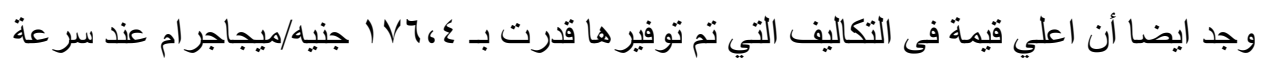

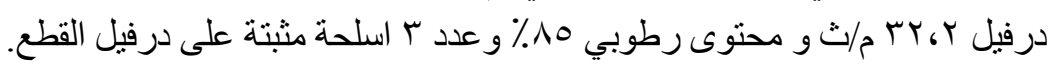

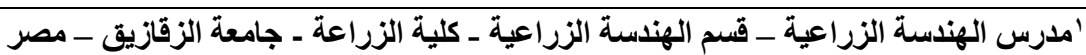

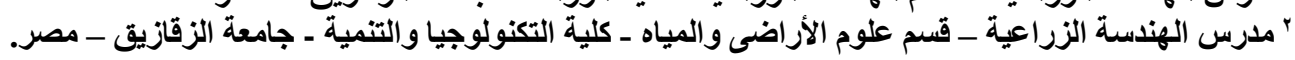

